\title{
Percepciones del plan de estudios de la Escuela de Comunicación de la UCR (2012) según sus estudiantes: Disonancias y coherencias con el modelo pedagógico constructivista \\ Perceptions of the UCR School of Mass Communication Science's Curriculum (2012), according to its students: dissonances and coherences with the constructivist pedagogical model
}

\section{Volumen 18, Número 3}

Setiembre-Diciembre

pp. 1-34

\section{Este número se publica el 1 de setiembre de 2018 \\ DOI: https://doi.org/10.15517/aie.v18i3.34045}

\author{
Lisbeth Araya Jiménez \\ Johan Espinoza Rojas
}

Revista indizada en REDALYC, SCIELO

Revista distribuida en las bases de datos:

LATINDEX, DOAJ, REDIB, IRESIE, CLASE, DIALNET, SHERPA/ROMEO, QUALIS-CAPES, MIAR

Revista registrada en los directorios:

ULRICH'S, REDIE, RINACE, OEI, MAESTROTECA, PREAL, $\underline{\text { CLACSO }}$ 


\title{
Percepciones del plan de estudios de la Escuela de Comunicación de la UCR (2012) según sus estudiantes: Disonancias y coherencias con el modelo pedagógico constructivista
}

Perceptions of the UCR School of Mass Communication Science's Curriculum (2012), according to its students: dissonances and coherences with the constructivist pedagogical model

\section{Lisbeth Araya Jiménez ${ }^{1}$ Johan Espinoza Rojas ${ }^{2}$}

\begin{abstract}
Resumen: La Escuela de Ciencias de la Comunicación Colectiva (ECCC) de la Universidad de Costa Rica, desde el año 2012, con el cambio de su plan de estudios continuó una serie de transformaciones que toman el constructivismo como fundamento de los procesos de aprendizaje. En estas líneas se delibera sobre las perspectivas epistémicas, críticas, y en menor medida metodológicas, que prevalecen en el plan de estudios 2012, según los criterios de sus estudiantes, a quienes se les consultó mediante un cuestionario en línea. Dicha encuesta se aplicó a inicio de 2015. Se consideró un margen de error del 7,4\%, un nivel de confianza del 95\% y un nivel de variabilidad máximo del $50 \%$, se definió una muestra estadísticamente representativa de 118 personas siendo la población total de 357 estudiantes. Sus opiniones, criterios y experiencia sistematizados en este artículo, procuran aportar a la reflexión y mejora constante de los métodos aprendizaje en la ECCC. Se considera que indagar en las opiniones del estudiantado, en relación con la formación recibida, es indispensable, y contribuye con algunas claves analíticas generales. Constituye, además, un aporte al área de la Educación, especialmente al evaluar las percepciones que, sobre un plan de estudios novedoso para el tiempo y contexto en el cual se implementó, tienen sus principales destinatarios. Los datos obtenidos son analizados a partir de la Teoría Crítica, la Teoría Crítica en la educación y el Constructivismo. Se concluye que el estudiantado percibe una coherencia de la ECCC con su visión pedagógica constructivista, no obstante, preocupa la demanda de empirismo y una cierta indiferencia/neutralidad respecto de algunas características del plan de estudios, lo que sugiere una contradicción. Se detalla, además, la necesidad de realizar mejoras, especialmente en la conexión existente entre los procesos de aprendizaje, y la relación con los contextos nacionales y latinoamericanos.
\end{abstract}

Palabras clave: plan de estudios, comunicación, investigación sobre el currículo, estudiante universitario.

Abstract: The University of Costa Rica's School of Mass Communication Sciences (ECCC) since 2012, with the change of its curriculum, has continued a series of transformations that take to the constructivism as the basis for the learning processes. In these lines we discuss the epistemic, critical and methodological perspectives that prevail in its curriculum, according to its students' criteria, who were consulted through an online questionnaire. This survey was applied at the beginning of 2015. Was considered a margin of error of $8 \%$, a level of confidence of $95 \%$ and a maximum level of variability of $50 \%$, and it was defined a statistically representative sample of 106 students. Their opinions, criteria and experience, systematized in this article, seek to contribute to the reflection and constant improvement of the learning methods in the ECCC. It is considered that investigating the opinions of students in relation to the education received is essential and provides some general analytical keys and for the transformation of both the ECCC, as well as other academic units, and constitute a humble contribution to the area of education, especially when evaluating the perceptions that, on a new curriculum for the time and context in which it was implemented, have their main recipients. The data obtained is analyzed from the Critical Theory, the Critical Theory on education and the Constructivism. It is concluded that the students perceive a coherence of the ECCC with its constructivist pedagogical vision, nevertheless, the demand for empiricism and a certain indifference / neutrality regarding some characteristics of the curriculum, its concerned and suggests a contradiction. The need for improvements is also detailed, especially in the connection between the teaching and learning processes and the relationship with the national and Latin American contexts.

Keywords: curriculum, communication, curriculum research, university students.

\footnotetext{
1 Docente e Investigadora de la Universidad de Costa Rica. Dirección electrónica: aravalis@gmail.com

2 Estudiante de la Maestría en Ciencias Cognoscitivas de la Universidad de Costa Rica.Dirección electrónica: johanespinozarojas@gmail.com
}

Artículo recibido: 6 de diciembre, 2017 Enviado a corrección: 19 de febrero, 2018 Aprobado: 25 de junio, 2018 


\section{Introducción}

La permanente reflexión sobre el hacer académico es tarea obligada en la Universidad de Costa Rica (UCR), sus centros, institutos de investigación y sus unidades académicas, especialmente, de cara a la continua búsqueda del mejoramiento de la calidad en sus distintos ámbitos y en procura de la excelencia académica. Esta premisa y toda la labor a ella vinculada, le ha permitido a la UCR estar, actualmente, entre las 500 mejores universidades del mundo, debido a la formación de sus docentes y las investigaciones realizadas.

En la Escuela de Ciencias de la Comunicación Colectiva (ECCC), que este 2018 celebra sus 50 años de existencia, esta tarea se ha asumido con seriedad y entusiasmo:

- Los procesos de acreditación (2005) y reacreditación (2011),

- a apertura del posgrado en Comunicación (2008),

- La inauguración del Centro de Investigación en Comunicación (CICOM) en el 2012,

- La creación, en el mismo año, de un nuevo Plan de Estudios, que abraza la perspectiva constructivista como enfoque pedagógico,

- La apertura de la nueva Maestría en Diseño de Lenguaje Audiovisual y Multimedia, (también 2012),

- La permanente evaluación de los cursos,

- El ordenamiento de los procesos asociados al diseño de los Trabajos Finales de Graduación (TFG) en los últimos años,

- La revisión permanente de los programas de los cursos por concentración,

- La gestión de espacios para el intercambio entre docentes y estudiantes,

- La creación de dos nuevas licenciaturas y,

- Ser sede en este 2018 del XIV Congreso de la Asociación Latinoamericana de Investigadores de la Comunicación (ALAIC), denominado Comunicación en sociedades diversas: Horizontes de inclusión, equidad y democracia, dan cuenta de tal seriedad y entusiasmo.

Desde su fundación, la ECCC ha pasado de priorizar el periodismo (como sus facultades y escuelas homólogas de esa época en Latinoamérica) a comprender la comunicación desde nuevas y cada vez más complejas áreas de labor de la profesión, desde las relaciones públicas, la publicidad, la producción audiovisual y más recientemente, la comunicación social. 
Es así que se hace necesario seguir auscultando rigurosamente los lugares desde los cuales se construye el conocimiento. En consecuencia, el presente escrito reflexiona sobre el Plan de Estudios de Bachillerato (2012) de la ECCC y especialmente sus disonancias y coherencias con el modelo pedagógico constructivista según la opinión de sus estudiantes.

Para ello es necesario preguntarnos ¿cómo se enseña y cómo se aprende en la ECCC? ¿Cuáles son los puntos de partida (epistémicos/ontológicos) del personal docente? ¿Qué aspiraciones constituyen la formación de profesionales? ¿Es el Plan de Estudios constructivista? ¿Cuáles son los principales aciertos y cuáles los retos en la concreción práctica de este enfoque pedagógico? Para obtener respuestas a estas preguntas, indagamos la percepción que, sobre el Plan de Estudios 2012, tiene el estudiantado del Bachillerato en Comunicación en la ECCC. En cuanto al concepto de percepción, este es entendido como

(...) el proceso cognitivo de la conciencia que consiste en el reconocimiento, interpretación y significación para la elaboración de juicios en torno a las sensaciones obtenidas del ambiente físico y social, en el que intervienen otros procesos psíquicos entre los que se encuentran el aprendizaje, la memoria y la simbolización. (Vargas Melgarejo, 1994, p. 48)

Se cree, al igual que Cánovas (2007, p. 2), en que esta manera de asumir el quehacer docente, ha plasmado lo que Schön (1992, p. 9) caracteriza como la tendencia de "pensar mientras se está haciendo", factor relevante tanto en la formación como en el ejercicio profesional de la comunicación.

\section{Breve revisión de literatura}

Ya otros estudios se han acercado a la investigación de la percepción del estudiantado sobre el plan de estudios en el que versa la carrera académica. Este es el caso del artículo de Carranza Ramírez (2012), quien, particularmente, analiza la percepción de estudiantes y del profesorado sobre el cambio realizado en la malla curricular de la carrera de enfermería en la Universidad de Costa Rica.

La indagación de la autora utilizó el método cualitativo, esto a partir de la técnica de la entrevista a profundidad, así como el grupo focal. Participaron cuatro profesoras entre los 38 y 52 años. También participaron tres estudiantes activos del nuevo plan, pero que estuvieron 
en el anterior. Por su parte, el grupo focal se realizó con 10 estudiantes matriculados en el nuevo plan de estudios.

Carranza Ramírez (2012) explica que el nuevo plan de estudios de la carrera de enfermería acoge, al igual que lo hizo la Escuela de Comunicación, al constructivismo como su principal basamento. No obstante, la investigadora encuentra que el estudiantado de esta carrera no ve de forma positiva este cambio. Así lo menciona la siguiente cita: "respecto del constructivismo, en mi opinión, no es mejor, porque nosotros no debemos hacer las cosas, sino deben ser los profes los que den las clases" (Carranza Ramírez, 2012, p.13).

Se trató de que este nuevo plan de estudios estuviera encaminado hacia la consecución de la mezcla entre teoría y práctica; no obstante, a partir de la percepción, sobre todo docente, se evidencia que "la práctica clínica que lleva al futuro o futura profesional a desarrollar destrezas en los diferentes ámbitos de su cotidianeidad, es señalada como insuficiente para el fortalecer el desarrollo profesional" (Carranza Ramírez, 2012, p.15). El estudiantado muestra también una percepción positiva ante el dimensionamiento de las habilidades de la investigación en la carrera, lo consideran como una herramienta que logra aumentar el conocimiento.

Otro de los antecedentes encontrados es el realizado por Caamal Montejo y Canto Herrera (2010), en este estudio se describe la opinión de estudiantes y docentes sobre la flexibilidad curricular en los planes de estudio de la Universidad Autónoma de Yucatán (UADY).

Los autores explican con determinación que:

(...) la flexibilidad curricular presupone un cambio de actitudes e implica ciertas tareas y características en dos actores principales que conforman la unidad básica en el proceso enseñanza-aprendizaje: el profesor y el alumno; conlleva a nuevas tareas para ambos, son afectadas sus relaciones, sus formas de organización y sus prácticas, de manera general, todas ellas están cambiando (Caamal Montejo y Canto Herrera, 2010, p. 2)

Este aspecto es de interés en el presente estudio, puesto que la modificación del plan de estudios de la Escuela de Comunicación cuenta con una visión de flexibilidad curricular, lo cual, como menciona la cita anterior, presupone una serie de modificaciones en las relaciones del proceso de enseñanza y aprendizaje entre el profesorado y el estudiantado. 
La metodología utilizada fue la cuantitativa, con la aplicación de una encuesta a 188 estudiantes y 61 docentes de planes flexibles.

El estudio encontró que la flexibilidad es guiada por la oferta de cursos más que por el propio deseo del estudiante de especializarse en alguna área de su interés. Por otra parte, la investigación concluye que ambos, tanto el estudiantado como el profesorado, como ya se mencionó, están de acuerdo con que esta flexibilidad curricular implica una serie de transformaciones, a saber: “(...) este tipo de cambios necesitan la transformación del pensamiento, pues se requiere moverse de un sistema de educación superior cerrado, en uno abierto, flexible e innovador (...)" (Caamal Montejo y Canto Herrera, 2010, p.8).

\section{Fundamentos teóricos}

Se considera que el enfoque crítico es el marco teórico que, de manera más contundente, se ha propuesto la reflexión profunda sobre las determinantes estructurales y estructurantes de la existencia humana. Siguiendo a Noguera, se afirma que la teoría crítica "se inspira en valores emancipatorios, al servicio de una transformación social que aumente los grados de autonomía y autorrealización de los individuos” (Noguera, 2002, pp.142-143).

Al mismo tiempo, el constructivismo, primero desde una perspectiva filosófica y luego desarrollado como enfoque pedagógico, prioriza la reflexión, el aprendizaje significativo y activo, al colocar a las personas como hacedoras del conocimiento, constructores de sus realidades y capaces de re-crearlas. Precisamente, este aprendizaje significativo es el cruce entre los conocimientos previos y el nuevo, tal y como desarrolla Moreira (2005). Este autor menciona que en este aprendizaje

(...) el aprendiz no es un receptor pasivo; muy al contrario. Debe hacer uso de los significados que ya internalizó, para poder captar los significados de los materiales educativos. En ese proceso, al mismo tiempo que está progresivamente diferenciando su estructura cognitiva, está también haciendo reconciliación integradora para poder identificar semejanzas y diferencias y reorganizar su conocimiento. O sea, el aprendiz construye su conocimiento, produce su conocimiento. (p. 4)

Es por lo anterior que son la teoría crítica y el constructivismo los puntos de partida teórico-conceptuales que sustentan estas meditaciones. A continuación, detallamos de seguido los conceptos específicos que las sustentan. 


\subsection{Teoría crítica}

Primeramente, se considera que la Escuela de Frankfurt abrió, en la filosofía y en las ciencias sociales, la gran oportunidad de sacudirse de un pensamiento arraigado en el que la persona de ciencia simplemente se dedicaba a observar y a tratar de explicar los fenómenos y no la búsqueda de transformaciones en los ámbitos sociales, políticos y económicos a partir de las herramientas dadas por las distintas disciplinas.

De aquí que este entramado teórico "(...) al mismo tiempo que aspira a una comprensión de la situación histórico-cultural de la sociedad, aspira, también a convertirse en su fuerza transformadora en medio de las luchas y las contradicciones sociales (...)" (Osorio, 2007 , p.106). La idea de una praxis, concepto que engloba lo anteriormente mencionado y tratado con amplio detalle en uno de los textos de Horkheimer (2003), que huelga decir, es además uno de los textos fundantes de la teoría crítica, nos permite pensar en la necesaria vinculación política de la práctica científica con la cotidianidad como tal. Agrega Alarcón Olguín (2002) que "(...) la praxis política en Horkheimer es vindicable en tanto configura una esfera de liberación sustantiva para transformar a la conciencia colectiva (...)" (párr. 12).

Esta transformación de la conciencia colectiva, como luego explica en su trabajo Alarcón Olguín (2002), no puede ser impuesta, pero sí parte de un proceso político paulatino que se atreva a considerar el bienestar social para aquellas y aquellos que han sido expulsados del sistema debido al egoísmo que este impregna.

La teoría crítica busca, pues, el develamiento de las estructuras hegemónicas que repercuten en el establecimiento de ideologías que vociferan

(....) la ausencia total de independencia y autonomía del hombre [y la mujer], dominado por otros hombres [y mujeres] instrumentalizando la razón para servirse con ella como un medio de poder tanto sobre la naturaleza como de los propios hombres [y mujeres]. (Lario Robles, 2005, p.1)

El uso de la razón, como instrumento para el beneficio de pocos, llevó a la teoría crítica a pensar en una razón que, al contrario, intente liberar las cadenas de la opresión de un sistema complejamente instaurado y sostenido. De acá que el componente de la educación se convierta en uno de los medios para poder alcanzar la meta propuesta.

En el siguiente apartado se discuten las generalidades de la aplicación de la teoría crítica en la educación, esto a partir del caso específico en análisis: la experiencia en la Escuela de Ciencias de la Comunicación Colectiva (ECCC). 


\subsubsection{Teoría crítica en la educación}

Menciona Roith (s.f.) que la pedagogía y, en general, la educación como disciplina tardó mucho en incorporar a la teoría crítica en su quehacer. Eso no fue, sino, hasta los años setenta del siglo pasado. Al incorporarse ampliamente la teoría crítica en la educación ha compartido una serie de características esenciales, las cuales se toman textualmente de la reflexión de González Arismendi (2009, p. 20):

a) La teoría crítica evalúa con carácter crítico la condición histórica social de la educación.

b) La teoría crítica de la educación debe influenciar positivamente la práctica pedagógica de [las y] los maestros.

c) La teoría crítica de la educación debe utilizar la crítica ideológica para poner en evidencia las condiciones socioeducativas y culturales (...)

e) La importancia de la teoría crítica de la educación no está supeditada a la crítica ideológica de la educación, sino que respalda diversas posibilidades de cambio y acción en el campo educativo.

Es así que la idea de un proceso de enseñanza y aprendizaje crítico se compromete con una educación que fomente transformaciones sociales a partir de la constitución de sujetos activadores, con base en la reflexión y el actuar suscitado en las aulas y demás espacios académicos.

Hay que mencionar que dichos procesos de enseñanza y aprendizaje parten de la visión que Montes de Oca y Machado (2011) comparten, al mencionar que:

hoy se reconoce la necesidad de una Didáctica centrada en el sujeto que aprende, lo cual exige enfocar la enseñanza como un proceso de orientación del aprendizaje, donde se creen las condiciones para que los estudiantes no solo se apropien de los conocimientos, sino que desarrollen habilidades, formen valores y adquieran estrategias que les permitan actuar de forma independiente, comprometida y creadora, para resolver los problemas a los que deberá enfrentarse en su futuro personal y profesional. (p. 476)

De hecho, en el Plan de Estudios del año 2012 y en el Plan de Desarrollo Estratégico de la ECCC (2010-2014), se consigna la propuesta de este centro de formar sujetos críticos. Específicamente, se detalla que "la Escuela está consciente de su responsabilidad de 
preparar a las personas para el cambio, generando hábitos de pensamiento crítico y de actuar responsable" (Universidad de Costa Rica, Escuela de Ciencias de la Comunicación Colectiva, 2015, p.1). Vinculado a lo anterior, los documentos hablan constantemente de considerar la comunicación como una herramienta promotora de cambios sociales, políticos y económicos, y comprometen a la población, tanto estudiantil como docente, a integrarse activamente a la construcción y aporte de ideas para la mejora ${ }^{4}$ de la sociedad costarricense.

Una educación crítica enlaza a docentes y estudiantes en la construcción de reflexiones y soluciones alejadas del sentido común y de aquellas ideologías que carcomen los lazos sociales solidarios, al interesarse más por un sentido de comunidad que por un individualismo tóxico.

El papel de la persona estudiante es tomar las herramientas facilitadas por sus docentes, reflexionarlas, hacerlas suyas a partir de su experiencia, deconstruirlas y reconstruirlas para aplicarlas en los contextos en los que participa a diario. Por su parte, el rol de la persona docente es guiar, sin imponer, la búsqueda de conocimientos alternos y constitutivos a la otredad para la emancipación social. En efecto, “(...) el profesorado tiene que tener como finalidad la emancipación, de lo contrario se limita a aplicar un conjunto de técnicas que no favorecerán el desarrollo de un pensamiento crítico, reflexivo y constructivo" (Margalef García y Pareja Roblin, 2008, p. 61).

La idea de una educación crítica es guiada, además, por una serie de cuestiones de suma importancia, las cuales se reseñan a partir de la reflexión suscitada por Moreira (2005):

1. Preguntas en lugar de respuestas: la no imposición de una única verdad fomenta, en la y el estudiante, la búsqueda de distintas maneras de conocimiento, y les aleja de un relativismo racional.

2. Múltiples conocimientos: alejarse de la homogeneización de la razón para entrar en la heterogeneización de esta. Mirar más allá de nuestro círculo de entendimiento. Es decir, romper las fronteras del campo clásico de enseñanza y aprendizaje.

3. Trabajar las múltiples realidades sociales a partir de la experiencia de las personas docentes y estudiantes.

4. Develar las estructuras dominantes para atacar los problemas que en ellas se engendran.

5. Asumir el error como parte integral en los procesos de enseñanza y aprendizaje. No hay que ocultarlo, sino utilizarlo como punto para la mejora constante.

\footnotetext{
${ }^{4}$ Mejora es entendida aquí como la búsqueda de una comunidad menos desigual, violenta y abusiva.
} 
6. Aprender a desaprender: la sociedad cambia constantemente, es necesario estar reconstruyendo lo ya aprendido.

7. El conocimiento es de por sí incertidumbre: no se debe dar todo por sentado.

8. Los procesos de enseñanza y aprendizaje son activos y no estáticos, se necesita de la participación de todas y todos.

Por último, Cánovas se pregunta ¿cómo llevar a cabo la labor académica en el actual contexto neoliberal y globalizado? La respuesta, dice la autora, se encuentra en la redimensión del perfil de la persona docente, caracterizado por una postura crítica, promotor del ejercicio selectivo de la información, así como del pensar desde la complejidad, atendiendo el bien común (2013).

En el siguiente apartado se discute la otra visión teórica que sustenta la discusión, es decir, el constructivismo.

\subsection{Constructivismo: la opción pedagógica elegida por la ECCC}

Con consciencia de la amplitud del constructivismo como enfoque pedagógico, así como de sus diversas vertientes teórico-metodológicas se prioriza en estas líneas el abordaje de los conceptos que se consideran de central relevancia para este artículo, a saber: la concepción del sujeto como activo, creador de conocimiento y transformador de realidades; el presupuesto de que el conocimiento nuevo se edifica sobre el anterior, así como de su vínculo intrínseco y multidimensional con el contexto donde tiene arraigo, el medular concepto de aprendizaje significativo y por último, la cavilación, nunca suficiente ni agotada, sobre el papel del profesorado y el estudiantado en los procesos de enseñanza y aprendizaje. Orienta la selección de dichos conceptos la revisión de la relación entre la teoría propuesta (desde la opción pedagógica elegida por la ECCC) y la práctica.

Uno de los planteamientos medulares del constructivismo, como se señaló, es la capacidad humana (para Piaget más orgánica, para Vigotsky más social) de buscarle sentido al mundo que nos rodea.

Según Soler (citada en González, 2012, p. 56) el constructivismo:

retoma las premisas epistemológicas del paradigma "interpretativo" y las aplica al aprendizaje, considerando la actividad cognoscitiva del aprendiz, quien organiza y da sentido a la experiencia individual... es la creencia de que [las y] los estudiantes son los 
protagonistas en su proceso de aprendizaje, al construir su propio conocimiento a partir de sus experiencias.

Precisamente, hincándose en el relevamiento de las experiencias individuales y colectivas, el constructivismo aduce que el conocimiento nuevo se construye basándose en el anterior (Sánchez, 2008). El pensamiento, desde el punto de vista Piagetiano, usa la información previa para edificar sobre ella lo novedoso y desconocido, sea encajándolo en la estructura anterior (asimilación), sea creando una nueva estructura (acomodación).

Para Ausbel y Robinson (citados en Sánchez, 2008, p. 56) el factor más importante que influye en el aprendizaje significativo de cualquier nueva idea, es el estado de la estructura cognoscitiva de la persona, los autores enfatizaban la idea de conocimientos organizados y estructurados alrededor de conceptos clave.

Respecto de la idea de aprendizaje significativo, esta se relaciona, adicionalmente, con los intereses del estudiantado. Es decir, los procesos de enseñanza y aprendizaje edificados desde los postulados constructivistas requieren conocer e incorporar los intereses e inquietudes particulares del estudiantado, en los diseños, el proceso formativo, e inclusive en la apropiación y uso de los conocimientos adquiridos.

La teoría Vigotskyana da mucha importancia a la instrucción como método más directo y eficaz "(...) cuyos instrumentos simbólicos tales como la investigación y el descubrimiento como métodos educativos, serán imprescindibles para el desarrollo de las nuevas generaciones" (Camarera Flores, citada en González 2012, pp. 55-56). Se trata así de aprender a aprender, de priorizar las preguntas más que las respuestas.

Se hace compleja así la propuesta del constructivismo, para Susan Francis (citada en González, 2012, p. 60), cada vez que se establece una estrategia didáctica no solo se indica cuáles son las fases, sino que, además, se define la función que tiene el cuerpo docente, el estudiantado, los métodos, los recursos y el contexto.

Respecto de este último elemento, en el constructivismo, el contexto tiene varios papeles; por un lado, los procesos de enseñanza y aprendizaje requieren un arraigo en los contextos en que se producen, al conocer sus determinantes para que el aprendizaje tenga sentido. Por otro lado, el aprendizaje debe servir para la vida cotidiana, debe ponerse en juego en la práctica, y desde allí, ser funcional en los quehaceres y oficios habituales. Esta dimensión de utilidad práctica requiere que lo aprendido sea puesto en entredicho, sea criticado. 
[Las y] los estudiantes necesitan explicar y cuestionar lo que se les dice, examinar el contenido nuevo en relación con contenido más familiar y construir estructuras (...) para interpretar situaciones nuevas, solucionar problemas, pensar y razonar y aprender de manera general. (Sánchez, 2008, p. 55)

Esto hace que tanto estudiantes como docentes sean co-responsables del proceso formativo, asumiendo, al mismo tiempo, autonomía y obligación. Si bien, en relación con los más clásicos esquemas, herencia de la educación bancaria (Freire, 2005), este postulado implica un cambio radical, un salto cualitativo que coloca en el centro del aprendizaje al estudiantado, para los tiempos que corren y con el reiterado ejercicio del constructivismo, esto aparece cada vez más natural y deseable.

Pese a lo anterior, parece que, en no pocos casos, se ha malinterpretado el lugar del profesorado en los procesos de enseñanza y aprendizaje, cuando se enmarcan en el enfoque constructivista, si existe una inadecuada comprensión de la centralidad del estudiantado, esto podría llevar a desdibujar el lugar de la persona docente, aclaramos con García Roca (citado en González, 2012):

Si el secreto de esta comunidad educativa consiste en aprender unos de otros, el docente tiene un papel de director de orquesta que ni disminuye su autoridad ni fragiliza su papel de enseñante, sino que adquiere la función de estimular a los otros a compartir sus funciones. (p. 58)

Entender lo anterior, implica comprender, al mismo tiempo, que desde la postura constructivista el profesorado debe abandonar, si aún los posee (o en su defecto los anhela), los criterios del conocimiento como verdad absoluta y la concentración de poder (algunas veces hasta abusiva e irrespetuosa) de su clásica investidura. Como señala Piedra (2010, p. 21), la persona docente ya no es sujeto central del saber o del poder, sino una y un facilitador de procesos. La clave parece ser construir una relación de mutuo respeto entre docentes y estudiantes, caldo de cultivo para la creación, la comprensión, las dudas y las críticas.

\section{Metodología}

Estas líneas sistematizan un breve estudio de alcance exploratorio-descriptivo, enfoque cuantitativo y diseño transversal, en el cual, con base en los postulados teóricos explicados 
anteriormente, se construyó un cuestionario (ver Anexo 1) que se aplicó en línea a estudiantes activos de la ECCC. En el encabezado de la encuesta, se consignaron todos los elementos del consentimiento informado vigentes para la investigación en la UCR. Las mediciones procuran tener un primer y general mapa de las ideas que, respecto del Plan de Estudios 2012 de la ECCC y su modelo pedagógico (constructivismo), tiene el estudiantado que, en el primer semestre del año 2015, cursaron asignaturas del bloque común.

En dicho cuestionario (véase el anexo 1) se consultó la opinión del estudiantado respecto del Plan de Estudios 2012, su visión sobre los contenidos prioritarios, tanto actuales como deseables, su adecuación al contexto, a las expectativas del estudiantado y su flexibilidad. Asimismo, se incluyeron preguntas sobre la labor docente, un reporte de (auto) compromiso, una definición de comunicación y las expectativas sobre el lugar ideal para trabajar al concluir la formación.

Por bloque común, entiéndanse aquellos cursos que debe aprobar el estudiantado independientemente de la concentración específica (periodismo, publicidad, relaciones públicas, comunicación audiovisual y multimedial y/o comunicación social) en la que se encuentra matriculado. La decisión metodológica de encuestar estudiantes del bloque común radica, precisamente, en que permite mayor nivel de representatividad, aun cuando no se trabajó con un muestreo por estratos, que da cuenta, con mucho mayor precisión, de las opiniones de la población estudiantil según concentración. Así, podemos con suficiente rigurosidad señalar, que las opiniones aquí sistematizadas representan las percepciones estudiantiles del bachillerato en comunicación.

Como corresponde a la naturaleza de los estudios cuantitativos, estos reflejan las percepciones de las personas consultadas, que se basan en sus experiencias, en el momento en que estas son solicitadas. Se concuerda con Madrigal Pana (PNUD y UCR, 2015, p. 8) cuando afirma que:

Estas percepciones son indicadores de interés, porque parten de la subjetividad de las personas y como tales pueden generar actitudes y comportamientos visibles (...). En este sentido es que se dice que las percepciones son tan importantes como la realidad misma.

La recolección de datos se realizó al cierre del primer semestre de 2015. Se trabajó considerando una población igual a 357 estudiantes del bachillerato en comunicación (según datos oficiales de 2015 de la ECCC), por lo que al considerar un margen de error del 7,4\%, 
un nivel de confianza del 95\% y un nivel de variabilidad máximo (del 50\%), se definió una muestra probabilística de 118 estudiantes. Cabe indicar que fue posible colectar datos para 10 cursos del bloque común, de un total de 14 cursos. En algunos casos, esos 10 cursos estaban siendo impartidos en varios horarios (grupos). En todas las tablas presentadas a continuación para mostrar los hallazgos, se trabajó con los porcentajes válidos.

\section{Resultados y discusión}

Seguidamente, se presentan los resultados obtenidos en la encuesta, los cuales se interpretan y discuten a la luz de la teoría crítica y el constructivismo.

\section{Tabla 1}

Costa Rica: Número de estudiantes del Bachillerato en Comunicación según concentración de formación, 2015. (valores nominales y relativos)

\begin{tabular}{|l|r|r|}
\hline \multicolumn{1}{|c|}{ Concentración } & Frecuencia & \multicolumn{1}{c|}{ Porcentaje } \\
\hline $\begin{array}{l}\text { Comunicación Audiovisual } \\
\text { y Multimedial }\end{array}$ & 40 & 33,9 \\
\hline Publicidad & 27 & 22,9 \\
\hline Relaciones Públicas & 23 & 19,5 \\
\hline Periodismo & 18 & 15,3 \\
\hline Comunicación Social & 10 & 8,4 \\
\hline Total & 118 & 100 \\
\hline
\end{tabular}

Fuente: Elaboración propia, con base en la información recolectada.

Como lo muestra la Tabla 1, la mayoría ${ }^{5}$ del estudiantado consultado pertenece a la concentración de Comunicación audiovisual y multimedial (34\%), luego se ubican quienes colocaron como principal énfasis Publicidad (23\%), seguidos de Relaciones Públicas $(19,5 \%)$, Periodismo (15\%), y en menor medida, quienes se forman en el más reciente énfasis de Comunicación Social $(8,5 \%)$. Es necesario señalar que resulta común, en la ECCC, que el estudiantado se forme simultáneamente en varias concentraciones. Los datos indicados corresponden a aquella definida como principal o primaria.

La mayoría de personas encuestadas ingresó a la carrera en los años $2015(35,5 \%)$ y 2013 (24\%), el siguiente grupo inició sus estudios en comunicación en el $2014(18,5 \%)$ y $2012(17 \%)$. En menor medida, se ubican quienes ingresaron en el $2011 \mathrm{o}$ antes de ese año (solamente $5 \%$ ), tal como se muestra en la Tabla 2.

\footnotetext{
5 Para efectos de este artículo, se entiende mayoría como la cantidad más elevada de estudiantes que seleccionaron una categoría y bien que pertenecen a ella, esa cantidad más elevada se expresa en porcentaje y por tanto su base es 100 .
} 
Tabla 2

Costa Rica: Número de estudiantes del Bachillerato en Comunicación según año de ingreso a la concentración, 2015. (valores nominales y relativos)

\begin{tabular}{|c|r|r|}
\hline $\begin{array}{c}\text { Año de ingreso } \\
\text { a la concentración }\end{array}$ & Frecuencia & Porcentaje \\
\hline Antes de 2011 & 1 & 0,8 \\
\hline 2011 & 5 & 4,2 \\
\hline 2012 & 20 & 16,9 \\
\hline 2013 & 28 & 23,7 \\
\hline 2014 & 22 & 18,6 \\
\hline 2015 & 42 & 35,6 \\
\hline Total & 118 & 100 \\
\hline
\end{tabular}

Fuente: Elaboración propia, con base en la información recolectada.

Para describir y analizar, en primera instancia, las opiniones del estudiantado sobre el Plan de Estudios 2012, se realizaron diez mediciones: adecuación del Plan al contexto nacional, a las expectativas del estudiantado; nivel de flexibilidad percibido y cualificación de dicha flexibilidad (entendida como la posibilidad de tomar y diseñar su propia ruta ante el plan); así como énfasis (percibido) de los cursos en la teoría o la práctica, o en ambos. Asimismo, se pidió una definición de comunicación, creada desde las particularidades de la malla curricular. Adicionalmente, se consultó las prioridades percibidas en la formación actual y aquella que, según el estudiantado, debería ser la prioridad. A continuación, se presentan los resultados y su respectivo análisis.

Cerca de la mitad $(46,6 \%)$ de la población estudiantil opinan que su formación está muy adecuada al contexto nacional, por cuanto solo un $2,5 \%$ señala que está poco adecuada a las realidades costarricenses. Sin embargo, llama la atención que el 50,9\% indique que la formación en la ECCC no está "ni mucho, ni poco" adecuada al contexto costarricense.

Al trabajar estos datos por concentración ,las diferencias en las opiniones no expresan amplias variaciones, pues se alteran escasamente entre "mucho" y "ni mucho ni poco ${ }^{6}$. Para Periodismo (55,56\% y 44,44\%), las Relaciones públicas (47,83\% y 52,17\%), la Comunicación audiovisual y multimedial (47,5\% y $45 \%$, el otro $7,5 \%$ restante se atribuye a la categoría "poco") y la Comunicación Social (60\% y 40\%). El dato es interesante en la Publicidad, en donde las personas encuestadas se inclinan más por la opción de "ni mucho

\footnotetext{
6 Los porcentajes de cada concentración se presentan de manera ordenada, el primero de ellos se vincula con la
} categoría "mucho" y el segundo con "ni mucho ni poco". 
ni poco." La teoría crítica pensaría en la vinculación necesaria con el contexto social para poder generar cambios, de lo contrario, lo que se hace es reproducir lo ya establecido. Por su parte, el constructivismo miraría, en esta vinculación, la posibilidad de generar un conocimiento a partir de las experiencias de las personas participantes.

Si bien, no podemos generalizar estos datos, en el caso de la ECCC, el énfasis de Publicidad, así como cualquier otro, debe crear conexiones directas con el contexto del país, fortaleciendo todos los vínculos que histórica y recientemente se han desarrollado (con organizaciones de la sociedad civil, del llamado tercer sector -asociaciones, cooperativas, organizaciones no gubernamentales-, empresas, sindicatos e instituciones públicas).

Esto último con el objetivo de alejarse de una comunicación que utilice como base de creación, las visiones ideológicas características de una identidad costarricense basada en el desprecio por la otredad (Molina Jiménez, 2005) que se evidencia en matices, desde el distanciamiento hasta la negación de su existencia. Además de esta dimensión política, desde el enfoque pedagógico constructivista, no tiene sentido una formación que no presente arraigo en el contexto en que se sitúa, ni pueda ser útil para comprender, apropiar y transformar dicho contexto.

Por ello, nos preguntamos ¿cuáles son los temas de la realidad nacional que no se están abordando en las aulas? O bien ¿cuáles son aquellos que podemos trabajar con mayor profundidad, dándoles más espacio y reflexión?

Por otra parte, si podemos cuestionar ese vínculo con el contexto nacional ¿qué relación tiene nuestra formación con los acontecimientos que se experimentan en el resto de Centroamérica y de América Latina? ¿Estamos reflexionando sobre las transformaciones políticas del resto del continente y del mundo? ¿Pensamos las nuevas relaciones entre izquierdas y derechas? ¿Visualizamos los ejercicios ciudadanos como espacios de disidencia? ¿Se entienden los vínculos entre los poderes político, económico y mediático? ¿Examinamos las estrategias para ejercer y las formas de abordar la corrupción en los discursos tanto mediáticos como ciudadanos? ¿Estamos tratando el creciente reforzamiento de antiguos conservadurismos -tanto religiosos como racistas, xenófobos y homofóbicos-? ¿Conversamos sobre las reflexiones vinculadas con las transformaciones contemporáneas en los ámbitos de las familias, la comprensión del género, la etnia y la sexualidad humana? ¿Internalizamos el desplazamiento -tanto geográfico como institucional formal y normativodel trabajo en la contemporaneidad? ¿Analizamos los procesos de creación y fomento de una subjetividad acorde a la racionalidad neoliberal? ¿Cuáles es el nivel de conocimiento y 
reflexión sobre los más recientes datos en relación con la pobreza, la desigualdad y las migraciones, por ejemplo? ¿Salud y educación? La lista es interminable. Esta es, sin duda, desde la opinión de quienes escriben, una reflexión que necesita ser asumida con la misma responsabilidad y entusiasmo (antes comentadas) por la ECCC.

Tabla 3

Costa Rica: Expectativas del estudiantado con respecto al nivel de adecuación del Plan de Estudios 2012 de la carrera de CCC. (valores nominales y relativos)

\begin{tabular}{|l|r|r|r|}
\hline $\begin{array}{c}\text { Nivel de } \\
\text { adecuación }\end{array}$ & Frecuencia & Porcentaje & $\begin{array}{c}\text { Porcentaje } \\
\text { acumulado a “más } \\
\text { de” }\end{array}$ \\
\hline Muy adecuado & 14 & 11,9 & 11,9 \\
\hline Adecuado & 84 & 71,2 & 83,1 \\
\hline Inadecuado & 17 & 14,4 & 97,5 \\
\hline Muy Inadecuado & 3 & 2,5 & 100 \\
\hline Total & 118 & 100 & \\
\hline
\end{tabular}

Fuente: Elaboración propia, con base en la información recolectada.

Como se muestra en la Tabla 3, el $83 \%$ del estudiantado considera que el Plan de Estudios del 2012 está adecuado o muy adecuado a sus expectativas, mientras que un 17\% lo cree inadecuado o muy inadecuado a lo que deseaba. Esta percepción coincide con lo propuesto por el constructivismo, para el cual, como se señaló, el estudiantado es parte activa del proceso de enseñanza y aprendizaje Parece, en consecuencia, coherente, que sus expectativas sean tenidas en cuenta en la elaboración del currículum y su puesta en práctica.

Respecto del nivel de flexibilidad percibido y la cualificación otorgada a dicha flexibilidad (ver Tablas 4 y 5), encontramos que la mayoría del estudiantado piensa que el Plan de Estudios 2012 es muy flexible (67\%), mientras que un porcentaje ínfimo (solo un 3\%) lo cree poco flexible. Un tercio del estudiantado indica "ni mucho ni poco". La mitad del estudiantado señala que esa flexibilidad es ventajosa o muy ventajosa (50\%), por cuanto solo $14 \%$ la define como desventajosa o muy desventajosa. De nuevo, en el medio, un 36\% se ubica en la neutralidad. Parece interesante profundizar en estudios posteriores y cualitativos sobre las particulares razones por las cuales se considera mayoritariamente ventajosa esa flexibilidad y, especialmente, auscultar ese dato que representa algún nivel de indiferencia. 
Tabla 4

Costa Rica: Percepción del estudiantado con respecto al nivel de flexibilidad del Plan de Estudios 2012 de la carrera de CCC, 2015 (valores nominales y relativos)

\begin{tabular}{|l|r|r|r|}
\hline $\begin{array}{c}\text { Nivel de } \\
\text { flexibilidad }\end{array}$ & Frecuencia & Porcentaje & $\begin{array}{r}\text { Porcentaje } \\
\text { acumulado } \\
\text { a "más de" }\end{array}$ \\
\hline Muy flexible & 79 & 66,9 & 66,9 \\
\hline Ni mucho ni poco & 35 & 29,7 & 96,6 \\
\hline Poco flexible & 4 & 3,4 & 100 \\
\hline Total & 118 & 100 & \\
\hline
\end{tabular}

Fuente: Elaboración propia, con base en la información recolectada.

Tabla 5

Costa Rica: Percepción del estudiantado con respecto al nivel de cualificación de la flexibilidad del Plan de Estudios 2012 de la carrera de CCC, 2015. (valores nominales y relativos)

\begin{tabular}{|l|r|r|r|}
\hline \multicolumn{1}{|c|}{ Cualificación } & Frecuencia & Porcentaje & $\begin{array}{c}\text { Porcentaje } \\
\text { acumulado } \\
\text { "a más de" }\end{array}$ \\
\hline Muy ventajosa & 15 & 12,7 & 12,7 \\
\hline Ventajosa & 44 & 37,3 & 50,0 \\
\hline Ni mucho ni poco & 43 & 36,4 & 86,4 \\
\hline Desventajosa & 12 & 10,2 & 96,6 \\
\hline Muy desventajosa & 4 & 3,4 & 100 \\
\hline Total & 118 & 100 & \\
\hline
\end{tabular}

Fuente: Elaboración propia, con base en la información recolectada.

Adicionalmente, en este grupo de variables relacionadas con la percepción del Plan, el 80\% del estudiantado indica que la mayoría de los cursos de su formación son teóricoprácticos; $18 \%$ dice que son mayoritariamente cursos teóricos, y solo un $2 \%$ considera que la mayor parte son cursos meramente prácticos. Esto, por un lado, se respalda en la decisión formal de la ECCC de definir todos los cursos del Plan 2012 como teórico-prácticos, y a la vez lo contradice en una medida, pues un nada despreciable $20 \%$ coloca una clara preeminencia de la teoría sobre la práctica. Resulta importante, a la hora de analizar estos datos, considerar que la mayoría del estudiantado encuestado está en su primer, segundo o tercer año de formación. En el currículum, por razones obvias, el énfasis en los talleres 
experienciales y las prácticas profesionales se coloca, mayoritaria aunque no exclusivamente, al cierre de la formación.

Llama la atención la importante cantidad de valores de las variables en estudio que se ubican en el medio (ni mucho ni poco), esto puede interpretarse de varias maneras; se intentó, metodológicamente, cerrar las opciones de respuestas, de modo que, en cada caso, las personas encuestadas deberían tomar alguna posición entre dos opciones antagónicas, con el objetivo de trazar líneas generales en la percepción. Sin embargo, pareciera que el estudiantado prefiere una postura más Aristotélica del justo medio ${ }^{7}$. Es posible, también, estar frente a un problema metodológico que puede ser considerado en futuros estudios ${ }^{8}$. Otra interpretación posible remite a la complejidad de la formación, las diferencias entre cursos, docentes, estudiantes, grupos y concentraciones, que hace difícil, a su vez, emitir una opinión general. Estos resultados evidencian la necesidad de realizar investigaciones específicas por concentración, y con enfoque cualitativo, que permitan, ahora, conocer en profundidad los datos que este estudio revela como interesantes, esa posición intermedia (ni mucho ni poco), es, sin duda, uno de ellos.

Resultan en extremo interesantes los resultados encontrados al preguntarle al estudiantado por lo que consideraban la primera (véase la Tabla 6), la segunda y la tercera prioridad del Plan de Estudios del año 2012. En todos los casos, las opciones de respuesta que ocupan el porcentaje más alto ${ }^{9}$ son tres: la comprensión profunda de conocimientos teórico-conceptuales, la apropiación de metodologías y técnicas de investigación, y la formación práctica para el ejercicio profesional.

\footnotetext{
7 Recuérdese la perspectiva ética de Aristóteles, que supone debemos siempre elegir, (para basar nuestro accionar, el cual debería dirigirse a la búsqueda permanente de la virtud), entre dos extremos viciosos. Esa elección, dice Aristóteles, conviene ubicarla en el punto medio entre los vicios, es lo que el autor llama "justo medio".

8 Parece necesario cerrar las opciones de respuesta, al eliminar las alternativas que permiten la neutralidad.

9 Refiere aquellas categorías que obtuvieron mayor concentración de respuesta, según frecuencia simple, expresada en porcentaje.
} 
Tabla 6

Costa Rica: Percepción del estudiantado con respecto a la prioridad actual del Plan de Estudios 2012 de la carrera de CCC, 2015.

(valores nominales y relativos)

\begin{tabular}{|l|r|r|}
\hline \multicolumn{1}{|c|}{ Prioridad actual } & Frecuencia & Porcentaje \\
\hline $\begin{array}{l}\text { La comprensión profunda de } \\
\text { conocimientos teórico- } \\
\text { conceptuales }\end{array}$ & 47 & 39,8 \\
\hline $\begin{array}{l}\text { La formación práctica para el } \\
\text { ejercicio profesional }\end{array}$ & 30 & 25,4 \\
\hline $\begin{array}{l}\text { La apropiación de } \\
\text { metodologías y técnicas de } \\
\text { investigación }\end{array}$ & 19 & 16,1 \\
\hline $\begin{array}{l}\text { La reflexión ética en el ejercicio } \\
\text { profesional }\end{array}$ & 8 & 6,8 \\
\hline $\begin{array}{l}\text { La formación en el uso y } \\
\text { manejo adecuado del } \\
\text { instrumental de la } \\
\text { comunicación (equipo y } \\
\text { aparataje) }\end{array}$ & 8 & \\
\hline $\begin{array}{l}\text { El análisis político del papel de } \\
\text { la comunicación en el contexto } \\
\text { socioeconómico }\end{array}$ & 6 & 6,8 \\
\hline Total & 118 & \\
\hline
\end{tabular}

Fuente: Elaboración propia, con base en la información recolectada.

Esto contrasta radicalmente con los porcentajes obtenidos en esas y otras categorías, cuando la consulta varía hacia cuál debería ser, según su punto de vista, la prioridad en la formación de la ECCC, información consignada en la Tabla 7.

El estudiantado aduce que la formación práctica para el ejercicio profesional debe ser la prioridad indiscutible $(57,6 \%)$, mientras que la comprensión profunda de conocimientos teórico-conceptuales se sitúa (de lejos y por mucho) en la segunda priorización (12,7\%). El análisis político del papel de la comunicación en el contexto socioeconómico ocupa el tercer lugar (11\%), seguido de la formación en el uso y manejo adecuado del instrumental de la comunicación (equipo y aparataje) con un 7,6\%. En los dos últimos puestos, la población estudiantil ubica la reflexión ética en el ejercicio profesional y la apropiación de metodologías y técnicas de investigación con un $6,8 \%$ y un $4,2 \%$ respectivamente.

Si vemos estos mismos datos por concentración de la carrera, el estudiantado de las concentraciones de Comunicación audiovisual y multimedial, Publicidad y Relaciones públicas (en ese orden) son las que más consideran que el Plan de Estudios debe centrarse en la formación y práctica del ejercicio profesional. Esto, quizás, se pueda explicar porque 
estos énfasis y sus profesionales se han caracterizado por el desarrollo de procesos y productos, más que por un trabajo teórico concienzudo (Vasallo de López y Fuentes Navarro, 2001). Esta tarea la han llevado a cabo otras disciplinas de las ciencias sociales, así, por ejemplo, la historia costarricense ha analizado la evolución de la publicidad ${ }^{10}$ en los medios - sobre todo los escritos- (Barboza Gutiérrez, 2011; Molina Jiménez, 2010; entre otros), lo mismo ocurre con los estudios en el campo de lo audiovisual. El periodismo se encuentra en un cuarto lugar, e igualmente este ha sido considerado en la disciplina de la comunicación desde lo práctico no más allá desde la reflexión teórica.

Parece llamativo cómo gran parte de los encuestados de Comunicación Social se sitúan en este mismo punto, cuando la carrera, en este más que en ningún otro énfasis, busca la reflexión de la comunicación como proceso social, político, cultural y económico. Sin embargo, en esta misma concentración, quienes respondieron el instrumento ven como necesario que haya una comprensión de los conocimientos teórico-conceptuales, apropiación de metodologías y técnicas de investigación y, también exista el debido análisis político de la comunicación en nuestro contexto.

\section{Tabla 7}

Costa Rica: Primera prioridad que debería tener del Plan de Estudios 2012, según la percepción del estudiantado, 2015

(valores nominales y relativos)

\begin{tabular}{|l|r|r|}
\hline \multicolumn{1}{|c|}{ Prioridad solicitada para el } & Frecuencia & Porcentaje \\
\hline $\begin{array}{l}\text { La formación práctica para } \\
\text { ejercicio profesional }\end{array}$ & 68 & 57,6 \\
\hline $\begin{array}{l}\text { La comprensión profunda de } \\
\text { conocimientos teórico- } \\
\text { conceptuales }\end{array}$ & 15 & 12,7 \\
\hline $\begin{array}{l}\text { El análisis político del papel de } \\
\text { la comunicación en el contexto } \\
\text { socioeconómico }\end{array}$ & 13 & 11,0 \\
\hline $\begin{array}{l}\text { La formación en el uso y } \\
\text { manejo adecuado del } \\
\text { instrumental de la comunicación } \\
\text { (equipo y aparataje) }\end{array}$ & 9 & 7,6 \\
\hline $\begin{array}{l}\text { La reflexión ética en el ejercicio } \\
\text { profesional }\end{array}$ & 8 & 6,8 \\
\hline $\begin{array}{l}\text { La apropiación de metodologías } \\
\text { y técnicas de investigación }\end{array}$ & 5 & 4,2 \\
\hline Total & 118 & 100 \\
\hline
\end{tabular}

Fuente: Elaboración propia con base en la información recolectada.

\footnotetext{
10 Salvando los estudios de la Dra. Patricia Vega Jiménez y la M.Sc. Virginia Mora Carvajal, que si bien son historiadoras, su formación en comunicación les ha permitido interesantes acercamientos desde la visión de esta disciplina, especialmente al entender a la comunicación como proceso social.
} 
A la luz de la perspectiva constructivista, estos datos parecen coherentes con la idea de que el aprendizaje debe servir para la vida cotidiana; en este caso, para el ejercicio empírico de la profesión. Sin embargo, la teoría crítica aporta elementos para considerar esto un exceso de pragmatismo, donde la reflexión, el debate teorético y la investigación quedan muy por debajo de lo empírico, pues únicamente cerca de un tercio (35\%) del cuerpo discente del bachillerato en la ECCC les coloca como prioridad del plan de estudios.

Esto contrasta de modo radical cuando se les pide una definición de comunicación, sintetizada en la Tabla 8, construida desde la malla curricular, allí el $43 \%$ aduce que la comunicación es fundamentalmente un proceso para la transformación y el cambio social, y un $41 \%$ la delimita como una serie de sentidos compartidos, socialmente construidos. Un 8,5\% se ubica en una perspectiva mucho más funcionalista de la comunicación, en el clásico Lasswelliano para reducirla a la transmisión de información de un emisor a un receptor. En menor medida se la asocia con la apropiación y el uso de tecnologías (4,2\%).

Tabla 8

Costa Rica: Percepción del estudiantado con respecto a la definición de comunicación, 2015. (valores nominales y relativos)

\begin{tabular}{|l|r|r|}
\hline \multicolumn{1}{|c|}{ Definición } & Frecuencia & Porcentaje \\
\hline $\begin{array}{l}\text { La base de un proceso para la } \\
\text { transformación y el cambio social }\end{array}$ & 51 & 43,2 \\
\hline $\begin{array}{l}\text { Una serie de sentidos } \\
\text { compartidos, socialmente } \\
\text { construidos }\end{array}$ & 48 & 40,7 \\
\hline $\begin{array}{l}\text { La transmisión de información de } \\
\text { un emisor a un receptor }\end{array}$ & 10 & 8,5 \\
\hline $\begin{array}{l}\text { La apropiación y uso de } \\
\text { tecnologías }\end{array}$ & 5 & 4,2 \\
\hline Otros & 4 & 3,4 \\
\hline Total & 118 & 100 \\
\hline
\end{tabular}

Fuente: Elaboración propia con base en la información recolectada.

Además de los ámbitos ya analizados, se construyó en la encuesta una sección para conocer las opiniones que, sobre el profesorado, tiene el estudiantado que cursa el bachillerato en comunicación. Se realizaron tres consultas: una sobre la forma en que se imparten las lecciones, otra sobre el punto de partida para generar conocimiento y la tercera sobre el interés prioritario del personal docente. 
Tabla 9

Costa Rica: Percepción del estudiantado con respecto al formato de clases, 2015. (valores nominales y relativos)

\begin{tabular}{|l|r|r|}
\hline \multicolumn{1}{|c|}{ Formato de las clases } & Frecuencia & Porcentaje \\
\hline En el formato clásico de clase magistral & 24 & 20,3 \\
\hline En un modelo participativo e interactivo & 94 & 79,7 \\
\hline Total & 118 & 100,0 \\
\hline
\end{tabular}

Fuente: Elaboración propia, con base en la información recolectada.

El $80 \%$ del estudiantado indica que las lecciones se edifican en un modelo participativo e interactivo, mientras el $20 \%$ restante señala que prevalece el formato clásico de clase magistral. En porcentajes cercanos a los anteriores, el $75 \%$ de las personas encuestadas aduce que la mayoría de sus docentes facilitan la creación de conocimiento en el aula, tomando como punto de partida su conocimiento. El $20 \%$ opina lo contrario.

Tabla 10

Costa Rica: Percepción del estudiantado con respecto del punto de partida para los procesos de enseñanza-aprendizaje, 2015.

(valores nominales y relativos)

\begin{tabular}{|l|r|r|}
\hline $\begin{array}{c}\text { Se parte del conocimiento } \\
\text { del estudiantado }\end{array}$ & Frecuencia & Porcentaje \\
\hline Sí & 89 & 75,4 \\
\hline No & 29 & 24,6 \\
\hline Total & 118 & 100,0 \\
\hline
\end{tabular}

Fuente: Elaboración propia, con base en la información recolectada.

Los datos consignados en las Tablas 9 y 10 resultan relevantes, para este análisis, en dos sentidos: en primera instancia, parece evidente que se está alcanzando, al menos en una dimensión, la promesa constructivista de clases participativas. Además de trabajarse bajo la lógica de la interactividad, lo que sería esperable en una Escuela de Comunicación. En segunda instancia, el hecho de que una quinta parte de las clases se impartan en el formato más clásico no necesariamente debe llevarnos a interpretar esto como negativo, pues, si bien se comprenden la participación y la interactividad como el ideal, este es un camino que se recorre progresivamente.

Resulta, además, indispensable señalar que las clases magistrales, en su sentido más estricto, tampoco deberían comprenderse como descartables y mucho menos, como negativas, pues la función de la persona docente, como se explicó en el marco teórico que sustenta este análisis, no pierde relevancia ni primacía. La ECCC cuenta con una plana docente cuya experiencia, trayectoria, recorrido académico, formación y méritos hacen no 
solo posible, sino deseable, este formato de enseñanza. Aunado a lo anterior, se considera necesario realizar estudios cualitativos posteriores, que permitan tener información mucho más detallada al respecto.

Tabla 11

Costa Rica: Percepción del estudiantado con respecto al interés del personal docente, 2015. (valores nominales y relativos)

\begin{tabular}{|l|r|r|}
\hline \multicolumn{1}{|c|}{ Interés } & Frecuencia & Porcentaje \\
\hline El aprendizaje de la o el estudiante & 61 & 51,7 \\
\hline Los contenidos a cubrir & 53 & 44,9 \\
\hline Usted como persona & 4 & 3,4 \\
\hline Total & 118 & 100 \\
\hline
\end{tabular}

Fuente: Elaboración propia, con base en la información recolectada.

Como se observa en la Tabla 11 , según un $52 \%$ del estudiantado, la mayoría de sus docentes se interesan especialmente por su aprendizaje; seguido de un $45 \%$ que prioriza los contenidos a cubrir. En el ínfimo porcentaje de 3\%, el estudiantado percibe que, como personas, son el interés preponderante de sus profesores. Esta opinión resulta muy relevante, ya que considerando que la ECCC ha asumido el modelo pedagógico constructivista, es posible preguntarse ¿dónde estará la distancia entre contenidos a cubrir e interés por el aprendizaje del estudiantado? ¿Cómo se construyó y especialmente, cómo puede saldarse esa brecha? ¿Cómo cubrir contenidos centrados en el aprendizaje? En las recomendaciones se esbozan algunas ideas a este respecto.

Además, se consultó al estudiantado sobre su compromiso personal con la formación (en una escala Likert de 0 a 10) y sus intereses laborales a futuro (ver Tabla 12).

Tabla 12

Costa Rica: Autoevaluación del compromiso del estudiantado con su formación, 2015.

\begin{tabular}{|c|r|r|r|}
\hline \multicolumn{1}{|c|}{ (valores nominales y relativos) } \\
\hline Autoevaluación & Frecuencia & Porcentaje & $\begin{array}{r}\text { Porcentaje } \\
\text { acumulado } \\
\text { "a más de" }\end{array}$ \\
\hline 3 & 1 & 0,8 & 0,8 \\
\hline 5 & 3 & 2,5 & 3,4 \\
\hline 6 & 2 & 1,7 & 5,1 \\
\hline 7 & 7 & 5,9 & 11,0 \\
\hline 8 & 40 & 33,9 & 44,9 \\
\hline 9 & 40 & 33,9 & 78,8 \\
\hline 10 & 25 & 21,2 & 100,0 \\
\hline Total & 118 & 100,0 & \\
\hline
\end{tabular}

Fuente: Elaboración propia, con base en la información recolectada. 
Un 5\% del estudiantado califican su compromiso con la formación con una nota igual o menor a 6 . Mientras que otro $6 \%$ la iguala a 7. Con mejor autoevaluación la mayoría la califica con 8 y 9 (34\% respectivamente) y el restante $21 \%$ se otorga la nota más alta, aduciendo un total compromiso con su formación.

La evaluación y la autoevaluación han sido, en pedagogía en particular y en la educación en general, un tema de permanente cavilación, al generar además la creación y revisión constante de instrumentos. Esta realidad no es ajena a la ECCC donde la evaluación es una práctica sistemática. En la autoevaluación realizada por el estudiantado, se evidencia una valoración positiva de su compromiso con la formación, esto es, $89 \%$ del estudiantado aduce que su compromiso es igual o superior a 8.

Esto puede interpretarse de varias maneras; por una parte, si retomamos los datos que se han venido elaborando en el marco del proyecto de investigación \#724-B2-006 titulado Seguimiento a la permanencia de la población estudiantil de la Universidad de Costa Rica, inscrito en el Instituto de Investigación en Educación (INIE) y liderado por la investigadora M.Sc. María Gabriela Regueyra Edelman, podemos usar como clave de lectura, para esta alta autoevaluación, el hecho de que la mayoría del estudiantado de la ECCC obtuvo en la Prueba de Aptitud Académica (PAA), que marca el ingreso a la carrera, un promedio de ingreso que se ubica en el rango de calificación entre los 650 a 750, con más peso en el segmento $650-700$ (porcentajes cercanos al $80 \%$ y con una media de $\left.82 \%{ }^{11}\right)^{12}$.

En promedio, un tercio del estudiantado que ingresó a Comunicación colectiva puntúa en la PAA entre los 700 y los $750^{13}$. Estos datos no son sorpresivos, pues el corte de ingreso de la carrera de comunicación se ha ubicado históricamente en muy altos rangos. Se aduce así, que esa alta autoevaluación se relaciona con que el estudiantado está consciente de sus habilidades y de sus posibilidades frente a las demandas del rendimiento académico.

Por otra parte, tanto la comunidad docente como la estudiantil ha expresado su percepción de que las calificaciones obtenidas, en general, por el estudiantado de la ECCC tienden a ser altas. Esto, sin embargo, no ha sido estudiado ni cualitativa ni cuantitativamente, sino que parece ser parte de los imaginarios colectivamente construidos y

\footnotetext{
11 Únicamente el año 2006 tiene un comportamiento atípico.

12 Esos datos se construyeron analizando al estudiantado que ingresó a la carrera entre el 2002 y el 2016 inclusive.

${ }^{13}$ Información elaborada por el Proyecto Seguimiento a la permanencia de la población estudiantil de la Universidad de Costa Rica, con información generada por el SISEPPOE a partir del SAE (junio 2016), Universidad de Costa Rica, junio 2016.
} 
sostenidos. Se cree muy importante realizar estudios rigurosos que profundicen en estas percepciones y en sus implicaciones en los procesos de enseñanza y aprendizaje.

Por último, uno de los datos más interesantes encontrado en este estudio y presentado en la Tabla 13, revela la autoconfianza del estudiantado, así como la perspectiva emprendedora que poseen, pues al ser colocados en el escenario del futuro trabajo y al fantasear con que tal decisión dependiera únicamente de sus deseos, la mitad (49\%) preferiría trabajar en su propia empresa. La segunda y lejana selección es una ONG (15\%), están luego quienes escogerían trabajar para el Estado (11\%), un medio masivo o una empresa privada (cerca del 10\% para ambos casos), y por último, las personas profesionales de la comunicación que buscarían colocarse en un medio comunitario de comunicación (6\%).

Tabla 13

Costa Rica: Percepción del estudiantado con respecto al lugar predilecto para laborar, 2015. (valores nominales y relativos)

\begin{tabular}{|l|r|r|}
\hline \multicolumn{1}{|c|}{ Lugar predilecto para trabajar } & Frecuencia & Porcentaje \\
\hline Una empresa fundada por usted mismo(a) & 58 & 49,2 \\
\hline Una organización no gubernamental (sociedad civil, ONG) & 18 & 15,3 \\
\hline Una institución del Estado & 13 & 11,0 \\
\hline Un medio masivo de comunicación & 11 & 9,3 \\
\hline Una empresa privada & 11 & 9,3 \\
\hline Un medio comunitario de comunicación & 7 & 5,9 \\
\hline Total & 118 & 100 \\
\hline
\end{tabular}

Fuente: Elaboración propia, con base en la información recolectada.

Este espíritu emprendedor es coherente con el tipo de subjetividad impulsada por la racionalidad neoliberal-capitalista, donde el sujeto individual, construido como autónomo y autosuficiente, es el responsable de su éxito académico y laboral. Además, el estudiantado tiene, en una importante cantidad de sus docentes, ejemplos de emprendedurismo exitoso, esto puede ser parte de lo compartido en los procesos de enseñanza aprendizaje, y podría, al menos en una medida, considerarse como un factor de modelaje.

\section{Conclusiones y recomendaciones}

\subsection{Conclusiones}

En general, es posible concluir que la ECCC ha mantenido un papel activo en los procesos de creación y revisión de su quehacer como unidad académica, procurando, de forma comprometida y vehemente, su transformación constante. Esto no significa que no 
existan aspectos de mejora, labores, funciones, formas y mecanismos usados en la docencia, la investigación y la acción social, que pueden y deban ser reformulados; al ser la tarea de pensarse y crearse una constante cuya meta última es la excelencia académica.

Es posible, además, afirmar, con base en los conceptos trabajados desde el enfoque pedagógico constructivista, que la ECCC aparece en la visión del estudiantado como bastante coherente con este modelo. De ello dan cuenta especialmente: su relación con el cumplimiento de las expectativas del estudiantado, la flexibilidad percibida del Plan de Estudios 2012, así como la positiva valoración de esta, la metodología participativa e interactiva utilizada, mayoritariamente, por el personal, así como la construcción de conocimiento nuevo con base en aquel adquirido previamente.

Es posible concluir, adicionalmente, que la percepción de estudiantado evidencia un alto nivel de coherencia entre lo propuesto por la ECCC, en su Plan de Estudios 2012, y las prácticas educativas, especialmente en la medida en que la comprensión profunda de conocimientos teórico-conceptuales, la apropiación de metodologías y técnicas de investigación y la formación práctica para el ejercicio profesional son, desde la opinión del estudiantado (y en ese orden), tres prioridades de dicho plan.

Es indispensable la relación con el contexto, tanto nacional como centroamericano y de América Latina, para colocar a las nuevas personas profesionales en la perspectiva globalizada e internacional que caracteriza tanto el trabajo como las relaciones en la contemporaneidad. El estrechamiento de los lazos con los diversos actores (organizacionales, comunitarios, vecinales, institucionales) de la realidad nacional permitiría, además, que el ejercicio de la comunicación aporte, de modo más directo, a la reflexión y la creación conjunta de soluciones -en la medida de las posibilidades y recursos- a los problemas más sentidos de la contemporaneidad costarricense y regional.

De estos problemas preocupan especialmente el resurgimiento de los conservadurismos, la pobreza y la desigualdad crecientes, las consecuencias políticas de las luchas anticorrupción, la creación de subjetividades propicias a la racionalidad neoliberal y capitalista, los cambios en los mercados de trabajo, el desmantelamiento del Estado -otrora llamado a garantir el bien común-, entre otros.

Por otra parte, los datos evidencian que es necesaria en la ECCC una ampliación y profundización de las perspectivas críticas, reflexionar sobre cómo y cuánto las diversas dimensiones del poder, sus imposiciones desde los discursos hegemónicos, sus estrategias y formas discursivas se construyen, silencian, desconocen, promueven, contradicen 0 
refuerzan en las realidades actuales (en la política, los medios, las instituciones, organizaciones y comunidades) de sus diversos actores. La perspectiva crítica, como marco teórico, aportaría además complejidad y profundidad a la comprensión de los procesos y fenómenos que se estudian desde la comunicación como disciplina.

En este sentido, preocupa especialmente identificar que la reflexión ética y teórica se ubica en los últimos escaños de los intereses del estudiantado, al privilegiarse el pragmatismo. Si bien, esto es comprensible en el marco de una socialización neoliberal que ha transformado la calidad y la cualidad de la educación secundaria, tanto como la priorización de una ética de la inmediatez y del individualismo, no puede, ni debe ser naturalizado en la educación superior en general, ni en los procesos de enseñanza y aprendizaje de la comunicación que se realizan en la ECCC. Por el contrario, el currículum y la práctica requieren de una amplia deliberación teorética que sustente el accionar.

A este respecto, pensando en el compromiso de estudiantado con su formación podemos afirmar que la autoevaluación parece optimista. No obstante, es necesario atender activamente esa décima parte del estudiantado, que reporta responsabilizarse escasamente con su proceso de formación profesional.

\subsection{Recomendaciones}

Tanto en la Universidad de Costa Rica, como en la ECCC, es sin duda pertinente e ineludible, la revisión permanente y rigurosa de los planes de estudio, los cursos otorgados, la metodología empleada en los procesos de enseñanza-aprendizaje y su relación con el contexto en que se inscriben. Estas líneas caracterizan, en amplios términos, las percepciones del estudiantado que cursó el bachillerato en comunicación en el I Semestre del año 2015. Sin embargo, se necesitan nuevas indagaciones que permitan conocer, con mayor profundidad, opiniones y percepciones tanto del estudiantado como del cuerpo docente. Se requiere, además, compilar y sistematizar evidencias, ir un paso más allá del sentir de las personas implicadas directas.

A este respecto, la ECCC ha impulsado interesantes acciones, citamos a continuación algunos ejemplos: la formación de sus docentes en cursos como "Desafíos didácticos en el proceso de enseñanza y aprendizaje de la Comunicación Social"; la creación y reformulación de instrumentos para la evaluación docente aplicados a todos los cursos, semestre a semestre; la inclusión activa del estudiantado en los espacios de toma de decisiones. Se 
considera necesario sistematizar estas acciones y evaluarlas, identificar buenas prácticas, logros y aciertos, así como retos, limitaciones y obstáculos por superar.

Recomendamos a la ECCC en particular, evaluar la posibilidad de realizar una serie de estudios que derivan de lo identificado con la presente investigación, investigaciones que indaguen en:

1. Las razones específicas por las cuales el estudiantado considera ventajosa la flexibilidad del Plan de Estudios 2012 y, especialmente, auscultar el dato que muestra cierto nivel de indiferencia respecto de dicha flexibilidad.

2. La opinión que supone que, en la ECCC, las calificaciones son, en general, altas.

3. La comprensión que tienen docentes y discentes sobre las clases llamadas magistrales, sus ventajas y desventajas, su importancia y pedagogía.

\section{Referencias}

Alarcón Olguín, Víctor. (2002). Max Horkheimer: los reductos de la crítica. Recuperado de http://www.uam.mx/difusion/revista/oct2002/alarcon.html

Barboza Gutiérrez, María. (2011). Publicidad e identidades. La publicidad de bebidas alcohólicas en Costa Rica (1950-1959). Reflexiones, 90(2), 37-51. Recuperado de https://revistas.ucr.ac.cr/index.php/reflexiones/article/view/1459/32376

Caamal Montejo, Febe y Canto Herrera, Pedro. (2010). Flexibilidad curricular: opinión de estudiantes $y$ docentes universitarios. Recuperado de http://www.comie.org.mx/congreso/memoriaelectronica/v10/pdf/area tematica 02/pone ncias/0480-F.pdf

Cánovas, Célica. (2007). Reflexión de la práctica docente en un proceso innovador. Actualidades Investigativas en Educación, 7(3), 1-19. DOI: https://doi.org/10.15517/aie.v7i3.9294

Cánovas, Célica. (2013). El quehacer docente universitario, hoy: complejidad y postura crítica en la superación de algunas contradicciones de la educación. Actualidades Investigativas en Educación, 13(3), 1-29. Doi https://doi.org/10.15517/aie.v13i3.12031

Carranza Ramírez, Alba. (2012). Percepción de docentes y estudiantes sobre el cambio curricular en enfermería. Universidad de Costa Rica. Enfermería en Costa Rica, 33(1), 11-16. Recuperado de http://www.binasss.sa.cr/revistas/enfermeria/v33n1/art2.pdf

Freire, Pablo. (2005). Pedagogía del Oprimido. Ciudad de México: Siglo XXI editores.

González Pérez, Esteban. (2012). Estrategias didácticas desde la perspectiva constructivista apoyadas con medios digitales para la Escuela de Bibliotecología y Ciencias de la Información, Universidad de Costa Rica (Tesis para optar por el grado de Maestría en Bibliotecología). Universidad de Costa Rica, San José, Costa Rica. 
González Arismendi, Samuel. (2009). La Teoría Crítica: hacia una perspectiva socio-histórica y emancipatoria de la práctica pedagógica. Cacumen, (5), 15-22.

Horkheimer, Max. (2003). Teoría Crítica. Buenos Aires, Argentina: Amorrortu.

Larios Robles, Vanessa. (2005). Teoría Crítica o Crítica Teórica. A Parte Rei, (38), 1-5.

Margalef García, Leonor y Pareja Roblin, Natalie. (2008). Un camino sin retorno: estrategias metodológicas de aprendizaje activo. Revista Interuniversitaria de Formación del Profesorado, 63(22,3), 47-62. Recuperado de https://dialnet.unirioja.es/descarga/articulo/2795620.pdf

Molina Jiménez, Iván. (2005). Costarricense por dicha. Identidad nacional y cambio cultural en Costa Rica durante los siglos XIX y XX. San José, Costa Rica: Editorial de la Universidad de Costa Rica.

Molina Jiménez, Iván. (2010). Los comunistas y la publicidad en Costa Rica. El caso del periódico Trabajo (1937-1948). Secuencia, Revista de historia y ciencias sociales, (77), 61-87. Recuperado http://secuencia.mora.edu.mx/index.php/Secuencia/article/view/1116/990

Montes de Oca, Nancy y Machado Ramírez, Evelio. (2011). Estrategias docentes y métodos de enseñanza-aprendizaje en la Educación Superior. Humanidades Médicas, 11(3), 475-488. Recuperado de http://scielo.sld.cu/scielo.php?pid=S1727$\underline{81202011000300005 \& \text { script=sci abstract }}$

Moreira, Marco. (2005). Aprendizaje significativo crítico. Indivisa, (6), 83-101. Recuperado de https://dialnet.unirioja.es/servlet/articulo?codigo=1340902

Noguera, José Antonio. (2002). El concepto de trabajo y la teoría social crítica. Papers, Revista de Sociología, (68), 141-168. Recuperado de https://dialnet.unirioja.es/servlet/articulo?codigo $=713533$

Osorio, Sergio. (2007). La Teoría Crítica de la sociedad de la Escuela de Frankfurt. Algunos presupuestos teórico-críticos. Revista Educación y Desarrollo Social, 1(1), 104-119. Recuperado de http://www.umng.edu.co/documents/63968/80132/RevNo1vol1.Art8.pdf

Piedra García, Luis. (2010). Estratégicas didácticas para la enseñanza universitaria en grupos grandes: un estudio de las estrategias existentes e implementadas para la creación de nuevas propuestas (Informe Final de Investigación N ${ }^{\circ}$ 724-A8-085). Recuperado de http://repositorio.inie.ucr.ac.cr/handle/123456789/351

Programa de las Naciones Unidas para el Desarrollo (PNUD) y Universidad de Costa Rica (UCR). (2015). Encuesta de Percepciones de Desigualdad. Recuperado de http://www.estadistica.ucr.ac.cr/contenido/noticias/Encuesta\%20Percepciones\%20de\% 20Desigualdad\%20dic08.pdf

Roith, Christian. (s.f.). La Teoría Crítica en la teoría educativa y los diseños curriculares de Wolfgang Klafki. Recuperado de http://www.ual.es/ chroith/pdf/Klafki.pdf 
Sánchez Murillo, Geovanny. (2008) Cómo realizar material interactivo: dirigido a docentes para apoyar el proceso de enseñanza-aprendizaje. San José: Coordinación Educativa y Cultural Centroamericana.

Schön, Donald. (1992). La formación de profesionales reflexivos. Hacia un nuevo diseño de la enseñanza y el aprendizaje en las profesiones. Madrid, España: Paidós.

Universidad de Costa Rica, Escuela de Ciencias de la Comunicación Colectiva. (2015). Plan de Estudios 2012. Recuperado de http://eccc.ucr.ac.cr/recursos/docs/guia academica/plan estudios 2012 resumen.pdf

Universidad de Costa Rica, Escuela de Ciencias de la Comunicación Colectiva. (2010). Plan de Desarrollo Estratégico (2010-2014). Recuperado de http://ucrcomunicacion.wdfiles.com/local-files/pde/Plan\%20de\%20Desarrollo\%20Estrat\%C3\%A9gico\%20ECCC\%2020102014.pdf

Vargas Melgarejo, Luz María. (1994). Sobre el concepto de percepción. Alteridades, 4(8), 4753. Recuperado de http://www.redalyc.org/html/747/74711353004/

Vasallo de López, María y Fuentes Navarro, Raúl. (2001). Comunicación, campo y objeto de estudio: perspectivas reflexivas latinoamericanas. México: UCOL. 


\section{Anexo 1: Cuestionario}

Los procesos de enseñanza-aprendizaje en la Escuela de

Ciencias de la Comunicación Colectiva de la Universidad de Costa Rica, desde la perspectiva estudiantil: epistemología, metodología y enfoque crítico.

\section{CUESTIONARIO}

Este es un estudio realizado en la Universidad de Costa Rica que busca conocer su opinión sobre las perspectivas epistemológicas, críticas y metodológicas que se dan en los procesos de enseñanza-aprendizaje de la comunicación, en la Escuela de Ciencias de la Comunicación Colectiva de la Universidad de Costa Rica.

Si acepta participar en este estudio se le pedirá que complete este cuestionario, en él se le consultan sus opiniones sobre el plan de estudios 2012, el rol del personal docente y el rol estudiantil.

Sus datos personales no serán consultados para asegurar el anonimato y la debida confidencialidad; la información será usada únicamente para fines académicos y de investigación. Los resultados de este estudio podrían aparecer en una publicación científica o ser divulgados en reuniones académicas pero de una manera anónima. Su participación es voluntaria y no implica ninguna molestia, ni riesgo -conocido, ni potencialpara su persona. Tiene el derecho de negarse a participar o a interrumpir su participación en la aplicación de la encuesta en cualquier momento.

Como resultado de su participación en esta investigación no obtendrá ningún beneficio directo, sin embargo, los resultados darán información para la toma de decisiones en los importantes procesos de revisión y mejora del quehacer de la ECCC.

Para los investigadores, Lisbeth Araya Jiménez y Johan Espinoza Rojas, será un placer brindarle mayor información.

Si usted está de acuerdo en participar, entonces inicie el cuestionario. Muchas gracias.

1. Indique la concentración en la que se forma (la principal, primaria)
1. Periodismo
2. Relaciones Públicas
3. Publicidad
4. Comunicación Audiovisual y Multimedial
5. Comunicación social

2. Indique el año en que ingresó a la concentración
1. 2015
2. 2014
3. 2013
4. 2012
5. 2011
6. Antes del 2011 
3. ¿Está la formación en la ECCC adecuada al contexto nacional?

1. Mucho

2. Ni mucho ni poco

3. Poco

4. ¿Cuán flexible considera el Plan de Estudios 2012?

1. Muy flexible

2. Ni mucho ni poco

3. Poco flexible

5. La flexibilidad del Plan de Estudios 2012 para usted ha sido

1. Muy ventajosa

2. Ventajosa

3. Ni mucho ni poco

4. Desventajosa

5. Muy desventajosa

6. Respecto de sus expectativas el plan de estudios 2012 resulta:

1. Muy adecuado

2. Adecuado

3. Inadecuado

4. Muy inadecuado

7. ¿Cuál es para usted la primera prioridad que el plan de estudios 2012 da a la formación que se ofrece actualmente en la ECCC?

1. La comprensión profunda de conocimientos teórico-conceptuales

2. La formación práctica para el ejercicio profesional

3. La apropiación de metodologías y técnicas de investigación

4. La reflexión ética en el ejercicio profesional

5. El análisis político del papel de la comunicación en el contexto socioeconómico

6. La formación en el uso y manejo adecuado del instrumental de la comunicación (equipo y aparataje).

8. ¿Cuál es para usted la segunda prioridad que el plan de estudios 2012 da a la formación que se ofrece actualmente en la ECCC?

1. La comprensión profunda de conocimientos teórico-conceptuales

2. La formación práctica para el ejercicio profesional

3. La apropiación de metodologías y técnicas de investigación

4. La reflexión ética en el ejercicio profesional

5. El análisis político del papel de la comunicación en el contexto socioeconómico

6. La formación en el uso y manejo adecuado del instrumental de la comunicación (equipo y aparataje).

9. ¿Cuál es para usted la tercera prioridad que el plan de estudios 2012 da a la formación que se ofrece actualmente en la ECCC?

1. La comprensión profunda de conocimientos teórico-conceptuales

2. La formación práctica para el ejercicio profesional

3. La apropiación de metodologías y técnicas de investigación

4. La reflexión ética en el ejercicio profesional

5. El análisis político del papel de la comunicación en el contexto socioeconómico 
6. La formación en el uso y manejo adecuado del instrumental de la comunicación (equipo y aparataje).

10. ¿Cuál es para usted la primera prioridad que debería tener el plan de estudios 2012 para la formación que se ofrece actualmente en la ECCC?

1. La comprensión profunda de conocimientos teórico-conceptuales

2. La formación práctica para el ejercicio profesional

3. La apropiación de metodologías y técnicas de investigación

4. La reflexión ética en el ejercicio profesional

5. El análisis político del papel de la comunicación en el contexto socioeconómico

6. La formación en el uso y manejo adecuado del instrumental de la comunicación (equipo y aparataje).

11. La mayoría de sus docentes se interesan especialmente por

a. Su aprendizaje

b. Su persona

c. Los contenidos a cubrir

12. En su formación la mayoría de los cursos son

1. Teóricos

2. Prácticos

3. Teórico-prácticos

4. Técnicos

13. En una escala de 0 a 10 , donde cero es nulo compromiso y 10 total compromiso ¿Cómo califica su nivel de compromiso con la formación en comunicación?

$\begin{array}{lllllllllll}0 & 1 & 2 & 3 & 4 & 5 & 6 & 7 & 8 & 9 & 10\end{array}$

14. Diría usted que en la formación que se da en la ECCC el conflicto se asume como:

1. Un evento/situación que la mayoría de las veces puede evitarse

2. Parte natural de todos los procesos de enseñanza aprendizaje

3. Un evento/situación inevitable, que lamentablemente hay que enfrentar

4. Un evento/situación que debe evidenciarse y reflexionarse

15. La mayoría de sus docentes facilitan la creación de conocimiento en el aula tomando como punto de partida el conocimiento estudiantil

1. $\mathrm{Si}$

2. No

16. Si tuviera que elegir, en atención a la malla curricular diría que comunicación en la ECCC es fundamentalmente

1. Una serie de sentidos compartidos, socialmente construidos.

2. La transmisión de información de un emisor a un receptor

3. La base de un proceso para la transformación y el cambio social

4. La apropiación y uso de tecnologías

5. Otro: ¿cuál? 
17. Diría usted que en la formación que se da en la ECCC la contradicción se asume como:

1. Un evento/situación que la mayoría de las veces puede evitarse

2. Parte natural de todos los procesos de enseñanza aprendizaje

3. Un evento/situación inevitable, que lamentablemente hay que enfrentar

4. Un evento/situación que debe evidenciarse y reflexionarse

18. La mayoría de las clases en la ECCC se dan

1. En el formato clásico de clase magistral

2. En un modelo participativo e interactivo

19. Si su futuro trabajo dependiera únicamente de su elección, preferiría trabajar en:

1. Una institución del Estado

2. Una organización no gubernamental (sociedad civil, ONG)

3. Un medio masivo de comunicación

4. Una empresa fundada por usted mismo(a)

5. Un medio comunitario de comunicación

6. Una empresa privada

20. ¿Por qué? 